Mathies, Richard A.

PROGRESS REPORT

$\mathrm{DOE} / \mathrm{ER} / 61125--\mathrm{Tl}$

DE92 006578

\title{
Ultrasensitive Fluorescence Detection of DNA
}

DE-FG-91ER61125

Investigators: Richard A. Mathies and Alexander N. Glazer Report Period: August 1, 1990 to December 1, 1991

Our research progress is summarized in seven publications and four patent filings. Reprints of the recently published papers have been enclosed to describe the technical details. The basic accomplishments and their importance are described below.

Paper (1) presents a brief description of our previous single molecule detection work, the fluorescence optimization theory, and our early fluorescence gel scanning results. This paper is a summary of the presentation that we gave at the SPIE Meeting in Los Angeles in January of 1990.

The complete description of our theory for the optimization of laser-excited fluorescence detection is presented in (2) which was recently published in Analytical Chemistry. This paper presents a method for optimizing the laser intensity and illumination or transit time for any laser-excited fluorescence detection experiment such as confocal scanning, single-molecule detection, capillary electrophoresis, and confocal microscopy. This paper presents a method for determining the intrinsic fluorescence lifetime and photodestruction parameters for a fluorescent probe. It then presents a general theory and method for choosing the optimum excitation conditions for that particular probe.

Quesada et al. (3) gives a complete description of the one-color, confocal fluorescence gel scanner and describes applications to the detection of DNA sequencing, DNA mapping, and pulsed field gels. The apparatus is described in sufficient detail to enable most labs to construct and use this apparatus. A wide variety of applications are presented to illustrate the general utility of this apparatus and method. We have also developed a simultaneous 2-color, confocal-fluorescence gel scanner which has been described in Publications 4 and 5 .

Publications 4,5 , and 6 report on the continuation of our studies of double-stranded (ds) DNA-intercalation complexes with fluorescent dyes. We have found that such complexes with the thiazole and oxazole derivatives whose structures are illustrated in the attached Figure have particularly favorable properties for high sensitivity detection of DNA. Fluorescent complexes of dsDNA, stable to electrophoresis, are formed with the TOTO and YOYO dyes. In the dsDNA-bound form, the TO and TOTO derivatives have absorption maxima at 510 and emission maxima at $530 \mathrm{~nm}$, whereas the YO and YOYO derivatives have absorption maxima at 490 and emission maxima at $510 \mathrm{~nm}$. Most important, TO and TOTO show a fluorescence enhancement upon binding to dsDNA of over 2,000-fold. By using dsDNA complexes with these dyes and with ethidium homodimer (Glazer, A.N., Peck, K., and Mathies, R.A., Proc. Natl. 
Acad. Sci. USA (1990) 87:3851-3855), we have accomplished

two-color detection of dsDNA in a single lane in agarose gels with picogram sensitivity and have shown that this methodology allows the determination of sizes of dsDNA fragments from 600 bp to 50 kbp with higher precision than hitherto reported.

Publication (7) presents a revolutionary new method for performing and detecting capillary electrophoresis. Although capillary electrophoresis is a rapid separation method with excellent resolution, the throughput is low because only one capillary can be run at a time. To resolve this problem, we have been working on the production of capillary array devices. Dr. Huang, who has been supported by a DOE Human Genome Postdoctoral Fellowship, has developed a new method for preparing capillary arrays and for detecting the fluorescent sequencing fragments. We have shown that capillary arrays can be detected with high sensitivity by scanning the planar array past our confocal detection system and sequentially detecting the signal from each capillary. Since the capillaries have small outside diameters, we can detect hundreds of capillaries with less than 1" of stage motion! Also, since capillary electrophoresis can be performed with high electric fields, the separation is complete in 1-2 hours. Our first publication (7) describes the separation of G-fragments on a four-capillary array. Single base resolution is observed out to 500 bases in under two hours. This establishes the feasibility of using the confocal detection system to detect capillary arrays.

\section{DISCLAIMER}

This report was prepared as an account of work sponsored by an agency of the United States Government. Neither the United States Government nor any agency thereof, nor any of their employees, makes any warranty, express or implied, or assumes any legal liability or responsibility for the accuracy, completeness, or usefulness of any information, apparatus, produch, or process disclosed, or represents that its use would not infringe prive trade name, trademark, ence herein to any specific commercial product, process, or service by tide ndorsement, recommanufacturer, or otherwise does not necessarily constitute or imply its endorsement, recon- views mendation, or favoring by the United States Government or any agency thereof. The vew and opinions of authors expressed herein do not 


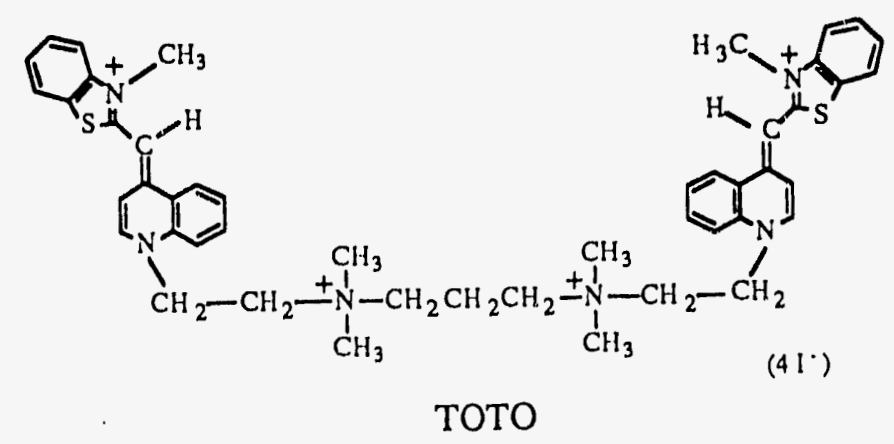

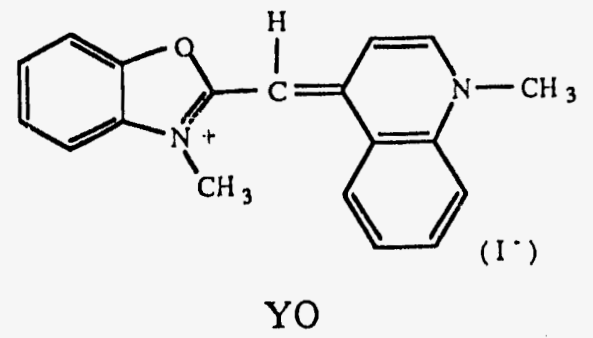

(SY-III-148)

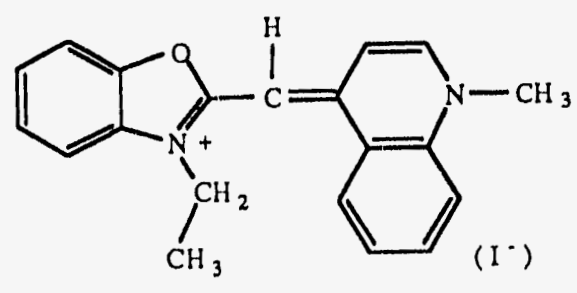

(SY-III-66)<smiles></smiles><smiles>C[As]1CCCC1</smiles>
$\mathrm{C}$<smiles>CCC=[SiH]=C(C)C</smiles>

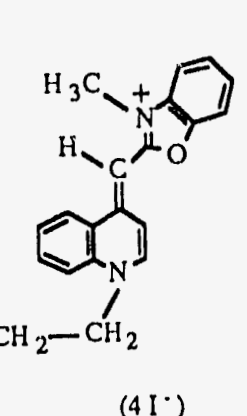<smiles></smiles><smiles>CCCCC[AsH]C</smiles><smiles>[SiH2]N=[SiH2]</smiles>
$\mathrm{CH}_{3}$ YOYO

(SY-III-127) 


\section{PLANS FOR THE NEXT BUDGET PERIOD}

1. High-throughput DNA sequencing using capillary arrays. To apply the capillary array method to DNA sequencing, we must detect all four sequencing fragments on a single capillary. Methods for labeling the DNA fragments with different fluorescent probes are well known. Now we need to fabricate a multicolor detection system for our capillary array detector to detect the different sequencing fragments. We have previously built a 2-color confocal scanner for gel detection so this should not present a problem. once a multicolor detection system is built, this apparatus would permit the detection of hundreds of sequencing lanes out to 500 bases in 1-2 hours.

2. DNA mapping using Capillary electrophoresis. We are setting up a confocal fluorescence detectjon system for the detection of high-molecular weight, double-stranded DNA fragments on non-denaturing gels. The goal is to explore the capabilities of confocal detection and intercalation dye complexes for the high-sensitivity detection of mapping fragments. This system will also be used to perform single-molecule detection of highmolecular weight DNA separated on a capillary electrophores is column.

3. Probe and method development for in situ hybridization. We are finishing the construction of a stage-scanned confocal

fluorescence microscope with digital photon counting deteztion. This apparatus should provide high signal-to-noise fluorescent images of chromosomes. First, the parameters of the scanning and excitation will be optimized using our fluorescence optimization theory. Then, the signal-to-noise of the confocal system will be critically compared with the capabilities of a cooled CCD detector on the same microscope. Finally, the microscope will be used to develop new fluorescent probes and methods for in situ hybridization studies using DNA intercalation complexes.

4. Applications of dsDNA-Dye Intercalation Complexes. The combination of the highly fluorescent dsuNA-intercalation dye complexes with the confocal scanning system permits detection of restriction fragments in the picogram range. This means that much smaller amounts of DNA are needed for such purposes as analysing restriction maps of cosmids and measuring overlap between clones in contigs. To exploit this capability to analyse samples of unknown low DNA content (for example, such as those obtained by PCR amplification), it is necessary to have a sensitive method for the quantitative determination of dsDNA concentration in solution. We are developing such a procedure utilizing the tightly bound intercalators TOTO and YOYO. Preliminary results indicate that reliable routine quantitation, utilizing conventional steady state fluorescence measurements, will be possible down to $5 \mathrm{ng}$ dsDNA per $\mathrm{ml}$. With this assay in place, we will explore the reliability of cosmid mapping and ordering by our procedure of running a standard mixture of DNA fragments stained with one dye and of unknown fragments stained with a second dye, both in the same lane. 
We also plan to examine the use of biotinylated asDNA-TOTO complexes as probes for in situ hybridization on chromosomes. We anticipate that detection with such multiply labeled probes will be much more sensitive than that possible with the currently used fluoresceinated avidin and Eluoresceinated anti-avidin antibody combinations.

\section{PUBLICATIONS STNCE LAST REVIEW}

1. R. A. Mathies, K. Peck and I. Stryer, High-sensitivity Single Molecule Fluorescence Detection, in Biojmaging and Two-dimensional spectroscopy, Proceedings of the International Society for Optical Engineering-SPIE 1205, 52-59 (1990).

2. Mathies, R. A., Peck, K. and Stryer, I. Optimization of High-Sensitivity Fluorescence Detection, Anal. Chem, 62, 1786-1791 (1990).

3. Quesada, M. A., Rye, H. S., Gingrich, J. C., Glazer, A. N., and Mathies, R. A. High-Sensitivity DNA Detection with a Laserexcited Confocal EJuorescence Gel Scanner, BioTechniques 10, $616-625$ (1991).

4. Rye, H. S., Quesada, M. A., Peck, K., Mathies, R. A. and Glazer, A. N. High-Sensitivity Two-Color Detection of DoubleStranded DNA with a Confocal Eluorescence Gel Scanner Using Ethidium Homodimer and Thiazole Orange, Nucleic Acids Research 19, $327-333$ (1991).

5. Rye, H. S., Yue, S., Quesada, M. A., Haughland, R. P., Mathies, R. A. and Glazer, A. N., Picogram Detection of Stable Dye-DNA Intercalation Complexes with a Two-Color, Laser-Excited Eluorescence Gel Scanner, Methods in Enzymology, Recombinant DNA, Part $H, E d . R$. Wu, in press.

6. Rye, H. S., Yue, S., Quesada, M. A., Haugland, R. P., Mathies, R. A. and Glazer, A. N. Picogram Detection of Stable Dye-DNA Intercalation Complexes with a Two-Color, Laser-Excited Confocal Eluorescence Gel Scanner, Human Genome III, San Diego CA, October 21-23, 1991, p. 33.

7. Huang, X. C., Quesada, M. A. and Mathies, R. A. Capillary Array Electrophoresis Using Laser-Excited Confocal Fluorescence Detection, Analytical Chemistry, submitted. 


\section{PATENT ACTIVITY SINCE LAST REVIEW}

1. U. S. Patent 4,979,824 issued December 25, 1990, HighSensitivity Fluorescent Single Particle and Single Molecule Detection Apparatus and Method, K. Peck, R. A. Mathies and I. Stryer.

2. Laser-Excited Confocal Fluorescence Gel Scanner, K. Peck and

R. A. Mathies, patent filed January 12, 1990 and now accepted.

3. Multichromophore Fluorescent Probes using DNA Intercalation Complexes, A. N. Glazer, K. Peck and R. A. Mathies, patent filed March 14, 1990. Serial No. 07/493,307

4. High-Speed, High-Throughput DNA Sequencer using Capillary Array Electrophoresis and Fluorescence Detection, X. C. Huang, M. Quesada and R. Mathies, disclosed to U. C. Berkeley on $8 / 9 / 91$, a formal filing is in preparation.

\section{PRESENTATIONS SINCE THE LAST REVIEW}

R. A. Mathies, "Single-Molecule Detection of Fluorophores at High Laser Powers," invited presentation at 'Scanning 91', Atlantic City NJ, April 9-12, 1991.

R. A. Mathies and A. N. Glazer, "High-sensitivity Fluorescence Detection of DNA" Human Genome Workshop, Santa Fe New Mexico, February 17-21, 1991.

A. N. Glazer, "Intercalation Dye-DNA Complexes and High-sensitivity Laser-Excited DNA Fluorescence Detection", invited presentation at Human Genome II, San Diego CA, October 22-24, 1990 .

R. A. Mathies, "High-Sensitivity DNA Detection with a Laser-Excited Confocal Fluorescence Gel Scanner, Analytical Chemistry Seminar at University of Wisconsin at Madison, September 20,1990 . 



$$
=
$$

